\title{
EL CIRUJANO DE AL-ÁNDALUS. APROXIMACIÓN A LA VIDA Y OBRA DE ABULCASIS DE LA MANO DE ANTONIO CAVANILLAS DE BLAS
}

\section{Al-Andalus' surgeon. An approximation to the life and work of Abulcasis by the hand of Antonio Cavanillas de Blas}

\author{
Yaiza Fei FERNÁNDEZ RAIGOSO \\ Facultad de Medicina y Ciencias de la Salud. Universidad de Oviedo (España). \\ Autor para correspondencia: Yaiza Fei Fernández Raigoso. \\ Correo electrónico: U0276195@uniovi.es
}

Recibido: 29 de junio de 2020

Aceptado: 8 de julio de 2020

\begin{abstract}
Resumen
Actualmente, mucha gente sigue pensando en «ciencias o letras» como dos ramas separadas y completamente distintas a la hora de elegir una carrera o simplemente de hacerse una idea de los intereses de una persona. Sin embargo, cada vez hay más esfuerzos para cambiar este concepto y dar a entender que no son opuestos, sino complementarios. Las letras se nutren de los avances de las ciencias y las ciencias necesitan de las letras para expresarse, avanzar y desarrollarse. Ejemplos claros son los libros que tratan temas médicos o relacionados con la medicina, ya sea desde la óptica del paciente y su entorno o desde la mirada del médico. Estos textos contribuyen a la formación humanística del médico y de los estudiantes de medicina: a cimentar el humanismo médico que debe presidir la relación entre el enfermo y el médico. En este trabajo aportamos una lectura de la relación entre literatura y medicina mediante la narración que Antonio Cavanillas de Blas hace de Abulcasis en su obra El Cirujano de al-Aldalus.
\end{abstract}

Palabras Clave: Abulcasis; Historia de la medicina; Medicina Árabe; Humanismo médico.

\section{Abstract}

Nowadays, many people still think of «science and humanities» as two separate branches, completely different when choosing a career or simply when imagining where a person's focus of 


\section{EL CIRUJANO DE AL-ÁNDALUS. APROXIMACIÓN A LA VIDA Y OBRA DE ABULCASIS DE LA MANO DE ANTONIO CAVANILLAS DE BLAS YAIZA FEI FERNÁNDEZ RAIGOSO}

interest lies on. Nevertheless, there is an increasing effort to change this point of view and make us realize they are not opposite, but rather complementary. Humanities nurture with science's advances and science needs humanities in order to express itself, advance and develop. Clear examples of this are the books that talk about medicine and medicine related themes. These texts promote the humanistic training of doctors and medicine students: creating a solid foundation of humanistic medicine, which ought to preside the patient- doctor relationship. In this article, we contribute to present the close relationship between literature and medicine analyzing the description Antonio Cavanillas de Blas gives us of Abulcasis in his work El Cirujano de al-Andalus.

KeyWord: Abulcasis; History of medicine; Arabic Medicine; Humanistic medicine.

"Donde quiera que se ama el arte de la medicina se ama también a la humanidad».

(Platón)

\section{Introducción}

En primer lugar, digamos unas palabras sobre el autor: Antonio Cavanillas de Blas. Antonio Cavanillas (Madrid, 1938) es cirujano y escritor, aunque, ya jubilado y debidamente enfundado el escalpelo, deberíamos quizá invertir los términos. Baqueteado por trochas y caminos ha recorrido medio mundo en pos siempre del arte, la cultura y la belleza estética.

Prolífico escritor con varias decenas de obras inéditas de ficción e históricas, ha publicado $E I$ Médico de Flandes (Plaza\&Janes), El León de Ojos Árabes (Grijalbo), El Prisionero de Argel (R.H.Mondadori), El Cirujano de al-Ándalus (La Esfera de los Libros), El Último Cruzado (Planeta México), Harald el Vikingo (La Esfera de los Libros) y La Desposada de Flandes (Áltera) ${ }^{1}$.

Habiendo hablado del autor, procedemos ya a hablar del libro. El cirujano de al- Ándalus, un título que anuncia tanto historia como ciencia y, sin embargo, una portada que no muestra nada de eso a primera vista. Solo un pequeño barco en el centro, detrás un sol, resplandeciente o poniente dependiendo de si ya eres conocedor de la historia que encierra o no. Este barco está enmarcado entre dos arcos, el diseño de estos dando pistas al lector, pues bien podrían pertenecer a la mezquita de la ciudad protagonista en esta historia: Córdoba. (Foto 1)

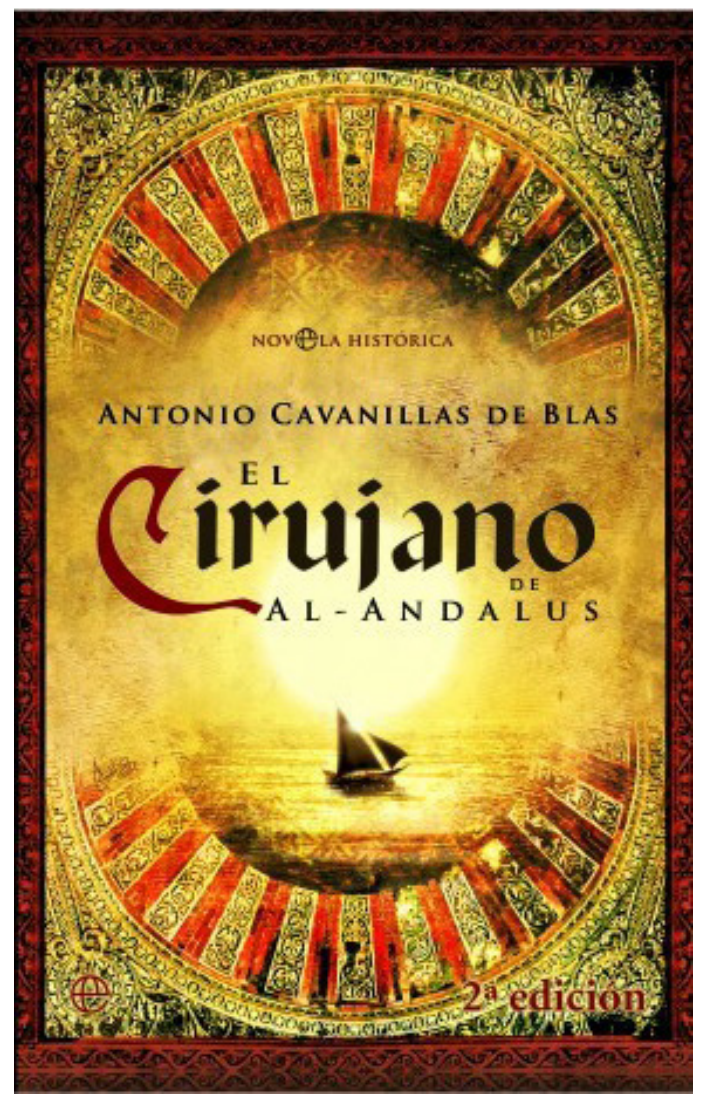

Foto 1

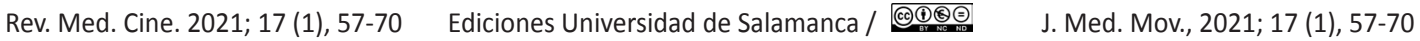




\section{EL CIRUJANO DE AL-ÁNDALUS. APROXIMACIÓN A LA VIDA Y OBRA DE ABULCASIS DE LA MANO DE ANTONIO CAVANILLAS DE BLAS YAIZA FEI FERNÁNDEZ RAIGOSO}

\section{Contexto histórico}

A pesar de que nos centraremos en los aspectos médicos, debemos situarnos, como bien nos permite hacer el autor, en la época y lugar en la que está ambientada la historia. Pues hay dos puntos continuos y centrales a lo largo de toda la obra: las ansias de avanzar y mejorar siempre en su profesión como médico, pero también la propia vida del protagonista y los personajes de su entorno. En cuanto a esto último, la historia se desarrolla principalmente en Córdoba, en el siglo $\mathrm{X}$.

Una Córdoba centro de conocimiento a lo largo del Mediterráneo bajo el reinado de Abderramán III (929-961) y su hijo Al-Hakam II (961-976) en lo que constituye el periodo de apogeo del Califato Omeya. "El califato que yo viví fue el momento supremo de Al-andalus y dudo que vuelva a repetirse. Ahora, al final de la vida, asisto a su lenta descomposición». Con todo, capital de intrigas palaciegas, desigualdades sociales y conflictos religiosos a los que se hacen mención. Al- Ándalus comparte la Península con pequeños reinos cristianos, poco desarrollados, pobres e incultos en comparación. Todavía necesitarán otros cuatro siglos para unificarse y tomar el poder. Esto también lo podemos ver con directa facilidad en cuanto a la profesión médica: «En los reinos cristianos, se castigaba a los médicos si no podían encontrar la cura. Cualquiera con un poco de cabeza sabe que los médicos podemos equivocarnos, pero es nuestro deber mejorar y curar vidas, no quitarlas. Ningún verdadero médico mataría a su paciente a propósito».
Más ampliamente, se nos presenta la sociedad multicultural y diversa de la época. Con una escala social en la que existe la esclavitud aunque este último punto no se nos presenta de manera cruda sino, más bien, de manera totalmente normal. No compartida por el protagonista sin embargo, ya que en una conversación con Omero el fiel esclavo que le lega su padrastro comenta, "entre todas las desgracias que afligen a los hombres en la tierra, ninguna mayor que no saber qué es la libertad». En verdad, hemos de hacer una pausa y reflexionar de vez en cuando mientras nos habla Abulcasis de su esclavo Omero, que nunca entendió lo que significaba la libertad, o de las esclavas a las que compraron él o su madre en el mercado que no podían estar más contentas del amo que les había tocado.

En este caso, hemos de reconocer al escritor, Cavanillas de Blas, que consigue sumergirnos de lleno en la Córdoba del siglo $X$, haciéndonos entender cómo piensa el protagonista, al que hace hablar desde la senectud, rememorando su vida y su obra. Esto es muy importante cuando se habla de la religión: la poligamia, los velos que cubren a las mujeres y hasta la prohibición de beber alcohol (la cual a veces se salta el protagonista), se nos explican de una manera racional y no bárbara.

No debemos olvidar que en la Córdoba califal florecieron la cultura, las ciencias y la medicina hasta el punto de que muchos hispanistas no han dudado en "considerar a la España musulmana como el más importante centro cultural del mundo en la Edad Media»². En el caso concreto de la medicina, la tabla 1 nos da una idea de lo prolífica que fue la medicina andalusí durante esta época y sus influencias en siglos posteriores. 


\section{EL CIRUJANO DE AL-ÁNDALUS. APROXIMACIÓN A LA VIDA Y OBRA DE ABULCASIS DE LA MANO DE ANTONIO CAVANILLAS DE BLAS YAIZA FEI FERNÁNDEZ RAIGOSO}

Tabla 1. Autores y obras representativas de la medicina andalusís,9,10

\begin{tabular}{|c|c|}
\hline Autor & Obra \\
\hline $\begin{array}{l}\text { Abu Yusuf Heysday ben } \\
\text { Shaprut (Siglo IX) }\end{array}$ & Experto en dietética y regímenes de adelgazamiento. Trató al rey leonés Sancho I el Gordo. \\
\hline Ibn Yuyal (Siglo IX) & $\begin{array}{l}\text { Escribió el Libro de la explicación de los nombres de los medicamentos simples tomados del libro } \\
\text { de Dioscórides, y otro sobre los errores más comunes de los médicos de la época. }\end{array}$ \\
\hline Ibn Habib (Siglo IX) & Escribió el Mujtasar fi l-tibb (Compendio de medicina) \\
\hline Arib b Saìd (siglo X) & $\begin{array}{l}\text { Escribió el famoso Calendario de Córdoba (sobre dietética) y el Libro de la generación del feto, el } \\
\text { tratamiento de las mujeres embarazadas y de los recién nacidos, primer tratado andalusí sobre } \\
\text { obstetricia }\end{array}$ \\
\hline $\begin{array}{l}\text { Abu al-Qasim Jalaf ibn } \\
\text { al-Abbas Al-Zahrawi } \\
\text { conocido como Abulcasis } \\
(936-1003)\end{array}$ & $\begin{array}{l}\text { Escribió Al-Tasrif (Libro de la práctica médica), enciclopedia médica en } 30 \text { libros cuya parte } \\
\text { quirúrgica fue la principal fuente de la cirugía posterior tanto islámica como europea }{ }^{1} \text {. } \\
\text { Propuso el uso de vendajes y curas impregnadas en vino. } \\
\text { Perfecciono la sujeción de piezas dentales con hilo de oro. } \\
\text { Destacó en las técnicas de litotomía y litotripsia. }\end{array}$ \\
\hline Ibn al-Wafid (1007-1074) & $\begin{array}{l}\text { Fundó el «Huerto del Rey» en Toledo, en el que realizó experimentos de aclimatación y de } \\
\text { fecundación artificial". }\end{array}$ \\
\hline $\begin{array}{l}\text { Abu Marwán Ibn Zhur } \\
\text { conocido como Avenzoar } \\
(1073-1162)\end{array}$ & $\begin{array}{l}\text { Su obra más importante es Theizir (Asistencias). Incluye descripciones de enfermedades del } \\
\text { corazón y de los oídos así como del parásito de la sarna. }\end{array}$ \\
\hline Averroes (1126-1198) & $\begin{array}{l}\text { Su obra Colliget (Libro sobre las generalidades de la medicina) cambió la forma de describir } \\
\text { las enfermedades y agrupó los estudios de medicina en los apartados Anatomía, Fisiología, } \\
\text { Patología, Sintomatología, Farmacología y Dietética, Conservación de la salud y Terapéutica. Es } \\
\text { el plan de estudios precursor de los actuales. }\end{array}$ \\
\hline Al-Gafiqi (siglo XII) & Escribió un Libro sobre los medicamentos simples. \\
\hline Maimónides (1135-1204) & $\begin{array}{l}\text { Su obra médica más conocida fue Fusul Musa (Aforismos de Moisés), colección de } 1500 \text { refranes } \\
\text { extractados de Galeno. } \\
\text { También escribió un tratado sobre las hemorroides, un libro sobre venenos y antídotos, una } \\
\text { disertación sobre el asma y otra sobre las relaciones sexuales. }\end{array}$ \\
\hline Ibn al Baytar (Siglo XIII) & $\begin{array}{l}\text { Su Colección de medicamentos y alimentos simples fue el primer vademécum realizado en la } \\
\text { península ibérica y contenía } 1400 \text { medicamentos y alimentos comentados con sus propiedades. }\end{array}$ \\
\hline $\begin{array}{l}\text { Ib Jatima, al-Saquri e Ibn } \\
\text { al-Jatib }\end{array}$ & $\begin{array}{l}\text { Propusieron que la propagación de la peste negra de } 1348 \text { se debía al contagio por contacto, una } \\
\text { idea novedosa para la época. }\end{array}$ \\
\hline \multicolumn{2}{|c|}{$\begin{array}{l}{ }^{1} \text { Algunos aforismos contenidos en el libro son: «No debe usarse la cirugía antes de tener la prueba de que todos los demás } \\
\text { remedios no producen efectos» "De ningún modo se debe realizar una operación por desesperación, ya se la cirugía sólo es } \\
\text { admisible cuando el estado general del enfermo hace probable el deseado éxito de la misma» } \\
2 \text { Siglos después haría lo mismo el médico Nicolás Monardes, que creó en Sevilla los «Huertos botánicos» para aclimatar las } \\
\text { plantas que venían de América. }\end{array}$} \\
\hline
\end{tabular}

No obstante, no podemos entender la medicina andalusí sin entender la medicina árabe en su conjunto y a sus grandes representantes, los cuales influyeron o fueron influidos por los anteriores. Citando a Cavanillas ${ }^{3}$, que recoge el sentir de la época: "Mientras la Europa cristiana se encontraba sumida en las tinieblas de la ignorancia, la medicina árabe disfrutaba de una etapa de esplendor científico. Los tres médicos más destacados de este periodo histórico fueron Razés, Avicena y el cordobés Averroes», entre otros que muestra la tabla 2. 


\section{EL CIRUJANO DE AL-ÁNDALUS. APROXIMACIÓN A LA VIDA Y OBRA DE ABULCASIS DE LA MANO DE ANTONIO CAVANILLAS DE BLAS YAIZA FEI FERNÁNDEZ RAIGOSO}

Tabla 2. Autores y obras representativas de medicina árabe medieval $\left.\right|^{5,9,10,11}$

\begin{tabular}{|l|l|}
\hline \multicolumn{1}{|c|}{ Autores } & \multicolumn{1}{c|}{ Obras } \\
\hline $\begin{array}{l}\text { Humain ibn Ishâq (sigloIX) } \\
\text { (Bagdad, Irak*) }\end{array}$ & $\begin{array}{l}\text { Introducción a la obra de Galeno Sobre el arte médico } \\
\text { Prominente en el campo de la oftalmología }\end{array}$ \\
\hline $\begin{array}{l}\text { Rhazes o Al- Razi (850- } \\
\text { 923) (Rayy, Irán) }\end{array}$ & $\begin{array}{l}\text { Kitab al-Mansuri (compendio de medicina teórica) }{ }^{\text {. }} \text {. Contiene las primeras monografías sobre } \\
\text { viruela y sarampión. } \\
\text { Al-Havi (enciclopedia de medicina práctica). } \\
\text { Estandarizó la utilización de tripas de animales como hilos de suturas (catgut). También introdujo } \\
\text { el uso sistemático de preparados químicos en terapéutica. }\end{array}$ \\
\hline $\begin{array}{l}\text { Avicena o Ibn Sina (980- } \\
\text { 1037) (Hamadán, Irán) }\end{array}$ & $\begin{array}{l}\text { Fue apodado El príncipe de los médicos. } \\
\text { Escribió Quanun (Canon de la medicina), obra en 50 volúmenes, que incluye todo el saber } \\
\text { médico y fue el tratado médico que mayor influencia tuvo hasta el siglo XVIII. }\end{array}$ \\
\hline $\begin{array}{l}\text { Ibn an-Nafis (Siglo XIII) } \\
\text { (Damasco, Siria) }\end{array}$ & $\begin{array}{l}\text { Editó un resumen del Canon de Avicena. } \\
\text { Describió por vez primera la circulación menor o pulmonar. No llegó a formularla como resultado } \\
\text { de la experimentación, sino del razonamiento, frente a lo que afirmaban tanto Galeno como } \\
\text { Avicena. }\end{array}$ \\
\hline $\begin{array}{l}\text { Ibn abi Usaybi'a (Siglo XIII) } \\
\text { (Damasco, Siria) }\end{array}$ & $\begin{array}{l}\text { Escribió Fuentes de información sobre las clases de médicos, que fundamentó la historiografía } \\
\text { árabe. }\end{array}$ \\
\hline Al-Kindi (Kufa, Irak) & $\begin{array}{l}\text { Escribió un intento de sistematización de lo conocido en «Sobre los grados en la composición de } \\
\text { los medicamentos». }\end{array}$ \\
\hline $\begin{array}{l}* \\
1 \text { Utilizando la distribución geopolítica actual }\end{array}$ \\
\hline
\end{tabular}

\section{Etapa de formación}

Abulcasis estudió medicina en la Córdoba califal, siendo alumno de su aljama o Medersa Superior donde se imparte un programa reglado que finaliza con el reconocimiento de la autoridad política y militar del momento: "La medicina se aprende en nuestra aljama. $Y$ no es cosa de un día. Se precisan cuatro años para que el gran visir extienda el certificado que te autoriza a ejercer». Da la impresión de que fue un alumno muy motivado y que desde muy pronto sintió la necesidad de investigar para avanzar en el conocimiento: «EI primer año se me fue en aprender nociones generales, rudimentos anatómicos y bases de botánica. Lo culmine con aprovechamiento, pero no estaba del todo satisfecho. Disfrutaba con lo que aprendía, pero sentía que me faltaba algo. Mis compañeros estudiaban de manera mecánica, sin andarse en honduras, memorizando datos, fechas y nombres, buscando la manera de labrarse un porvenir y ganarse la vida holgadamente. Yo anhelaba otra cosa. [...] Sin investigación no había adelanto».
Por otra parte, fue respetuoso con sus profesores y maestros. En este sentido, Cavanillas pone en boca de Abulcasis: "soy un hombre de ciencia. La recibí de los profesores a los que reverencio, aquí, a mi lado y mi obligación es transmitirla a mis alumnos. Cualquiera de ellos, en muy poco tiempo, será capaz de obrar lo que muchos de vosotros tomáis como prodigio y sólo es la aplicación de un discreto saber, de algo de erudición, el atisbo de una sabiduría que sólo Alá domina.» Buena parte de estas reflexiones, exclusión hecha de la invocación religiosa de sabiduría, permanecen en nuestros días y están contenidas en la definición de profesionalismo médico ${ }^{4}$.

En su formación también influyeron tres profesores de la escuela médica: Al- Qurtubí, que también era el director de la medersa; Al- Mayuri, encargado de botánica y anatomía; y Heysday Ben Saprut, médico de Abderrahmán III. Este último, consiguió eliminar el sobrepeso del rey leonés Sancho I el Gordo ${ }^{5}$, hecho que en el libro se atribuye a Abulcasis. 


\section{EL CIRUJANO DE AL-ÁNDALUS. APROXIMACIÓN A LA VIDA Y OBRA DE ABULCASIS DE LA MANO DE ANTONIO CAVANILLAS DE BLAS YAIZA FEI FERNÁNDEZ RAIGOSO}

Sin embargo, nada se sabe de su familia, sus ascendientes, ni descendientes, ni tampoco algo que es todavía más inusual que lo omitan los biógrafos: quiénes fueron sus maestros directos y sus discípulos. Da la impresión de que hubo una especie de pacto de silencio sobre nuestro autor. Bien pudo ser discípulo de 'Arīb Ibn Sa'īd, nacido en Córdoba sobre el 918 y que falleció en la misma ciudad en el año 980.

Fue también contemporáneo suyo 'Abd al-Raḥmān Ibn Isḥāq al-Haytam, del que solo sabemos que vive en la Córdoba del siglo $X$ y es autor de cuatro obras de temas médicos diversos, todas ellas perdidas, pero de las que conocemos sus títulos por Ibn Abī Ușaybi'a. Lo mismo sucede con Abū Ayyūd Sulaymān Ibn Ḥassān, más conocido como Ibn Ŷulŷul (943-después de 994), historiador de la medicina y buen conocedor de las propiedades de los medicamentos simples. Junto con el médico judío Ḥasdāy Ibn Šaprūț y el monje bizantino Nikolas, abordará la tarea de ofrecer la versión cordobesa de la Materia Médica de Dioscórides ${ }^{6}$.

\section{Actividad profesional}

Abulcasis ejerció de cirujano en Córdoba dejando constancia de una actividad respetada tanto por los poderosos como por los humildes. Fue médico personal del Gran Visir (Al Hakan II, y del hijo que le sucedió dominado por Al Mansur) en una época convulsa en guerras continuas y en la que las intrigas palaciegas y las luchas de religión (cita Abulcasis las palabras de uno de sus profesores: "El día en que los ulemas impongan su ley se acabará el dominio cultural del islam». Esto ocurrirá porque «Moríamos de éxito científico porque las escuelas y Cortes musulmanas estaban formadas por gentes de diversas razas, nacionalidades y religiones») amenazan con destruir la convivencia.

También recuerda que "Los médicos éramos protegidos por las leyes califales» que tenían muy claro que "Solo hay dos ciencias, la teología, o salvación del alma y la medicina, o salvación del cuerpo, dice el profeta. De ahí la estimación por la medicina en el islam». Esto explica también el contraste entre los reinos cristianos y los musulmanes musulmanes, ya comentado.

Cavanillas deja constancia en su novela de que Abulcasis alcanza el mayor rango en la enseñanza, de que dedica esfuerzos importantes a la formación de los estudiantes y de que organiza frecuentes sesiones ("De acuerdo con Al-Qurtubi, organicé un seminario para explicar a los estudiantes la operación, los síntomas que produce la estruma patológica y su tratamiento médicoquirúrgico, acompañado todo de láminas que diseñé y amplié en la pizarra») de demostración para enriquecer la enseñanza y el aprendizaje. El fruto de las reflexiones sobre su actividad profesional y sus aprendizajes en el ejercicio de la medicina quedó reflejado en su tratado Al-Tasrif (Libro de la práctica médica).

Si simplificamos la jerarquía médica podríamos decir que el hakim, es el sabio por antonomasia; el tabib, es el profesional con inclinación hacia la cirugía; y el mutatab es el ayudante de los anteriores. Abulcasis nos dice: "con treinta años, fui entronizado como hakim, reconocido poseedor de la excelencia intelectual y ética de un verdadero sabio». Sin embargo, también podría considerársele un tabib ya que, como veremos más adelante, la cirugía formó una parte importante de su actividad médica.

Como curiosidad, la palabra tabib (طبب) es la que se sigue utilizando en árabe para nombrar a un médico.

\section{La Enfermedad en la Obra de Abulcasis}

Para conocer las características de las enfermedades que Cavanillas de Blas describe en la obra de nuestro personaje, hemos intentado encontrar las características que suelen, según algunos autores, reunir los textos literarios 
relacionados con la enfermedad y que son: 1 ) Cuentan historias únicas; 2 ) Cuentan historias en primera persona; 3) Aportan diferentes estrategias narrativas; 4) Ponderan el componente social de la enfermedad; 5) Proponen un papel educativo para la enfermedad; 6) Proponen la enfermedad como una oportunidad de reflexión; 7) Reconocen la limitación del lenguaje para expresar lo que se siente; 8) Proponen la narrativa como una forma de vencer las limitaciones de la expresión oral y 9) Reconocen en la narración un proceso curativo ${ }^{7}$ (Foto 2 ).

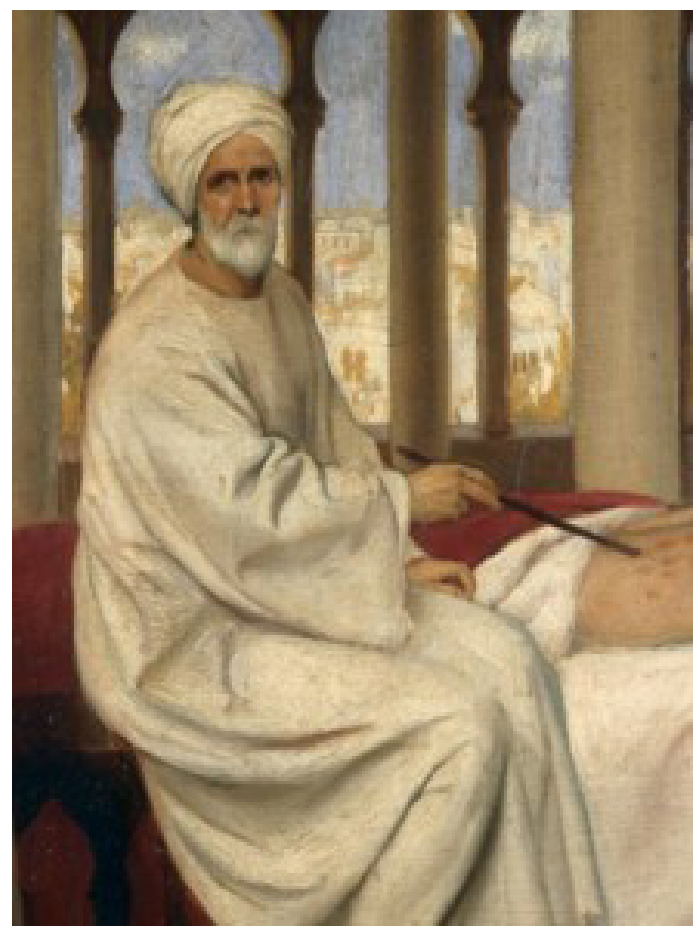

Foto 2. Retrato de Abulcasis según Ernst Board.

Sin embargo, El cirujano de al-Ándalus, como su nombre indica, no sigue la historia de un enfermo, sino de un médico. Esto quiere decir que no vemos una enfermedad en concreto ni las vivencias de un enfermo, sino que más bien podría describirse como una ventana a la profesión médica y, una vez asomados por la ventana, a las vivencias de los pacientes, cada historia siendo única a su vez. Por ello, reorientamos nuestro estudio a los siguientes aspectos: 1 ) La imagen del médico prototipo o ideal; 2) La descripción detallada de enfermedades y sus tratamientos; 3) La visión de la enfermedad y del enfermo a ojos del médico y 4) La influencia de la política y la religión en el ejercicio de la profesión.

\section{La imagen del médico prototipo o ideal}

De las palabras y acciones atribuidas a Abulcasis pueden destacarse varios aspectos, tales como: un afán por aprender desde joven, curioso por descubrir la lógica detrás de las cosas lo que le conduce hacia la vocación por la medicina; valores médicos como amabilidad, compasión, justicia, humildad tanto en su trabajo como en su vida personal, profesionalidad y destreza a la hora de dar juicios médicos o practicar cirugías, y aumento de la experiencia a medida que se desarrolla la historia y, con ella, su vida. Entre los rasgos más característicos podemos destacar:

\section{Curiosidad, vocación}

Abulcasis deja constancia de aspectos relacionados con la vocación profesional y sus valores en expresiones como las que siguen: «Mis jornadas eran agotadoras, pero a cambio hacia lo que amaba y disfrutaba con ello" y "Hubo días que oscurecía y seguía viendo pacientes», que tienen que ver con el altruismo; "Como científico, soy escéptico en líneas generales. Sólo creo lo que veo con mis ojos", "Le hablé entonces de la ciencia médica, de la cirugía y de la única manera de avanzar en ella: la experimentación» que tienen 
que ver con el componente científico del profesionalismo médico. De hecho, en un momento determinado indica que "En realidad la Meca fue el pretexto. [...] Mi peregrinaje fue para ver caras nuevas, comprobar qué tipo de cirugía se hacía en Arabia, Constantinopla, Atenas, Roma o Nápoles». Persiguiendo la razón última de encontrar una explicación a la enfermedad "Tiene que haber una explicación, pues en la medicina la hay siempre. Otra cosa es que sepamos encontrarla». No en vano "Todo ello (lo que se enseñaba) era lógico, pero sólo teórico». Por eso reflexiona molesto: «¿Quién pudiera disponer de un cadáver? Maldije en mi interior las atrasadas leyes que, basándose en prejuicios religiosos y atávicos, impedían a los islamitas trabajar con cuerpos muertos».

\section{Amabilidad, compasión, justicia}

La amabilidad y compasión podemos verla en todos los aspectos de su vida, no solo en los médicos. Es el caso de su trato digno a todos sus trabajadores o el hecho de que nunca haga distinciones de clase o género. Dentro de su profesión, muestra rasgos de humildad al reconocer el mismo que "También un hakim ignora muchas cosas». Como "no trabaja sólo por una remuneración que premie su larga formación y su trabajo responsable», vive de acuerdo a los valores de la profesión y enseñanza médica, que ponen al paciente por encima de cualquier cosa superficial como puede ser el rango social. Por ello, "no se cobra igual a un terrateniente que a un obrero". Se debe cobrar a cada uno lo que pueda pagar: "yo sólo cobro las consultas o intervenciones que se hacen de intención y en pacientes pudientes», que alude al ejercicio profesional centrado en el enfermo y no en el enriquecimiento personal (Foto 3).

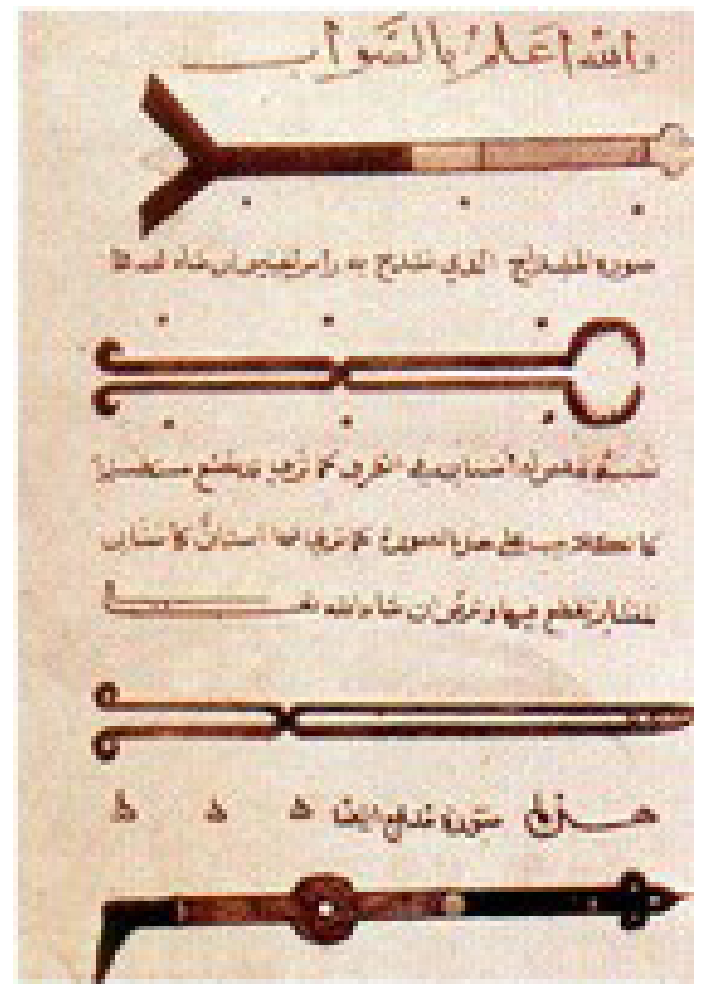

Foto 3. Al-Tasrif de Abulcasis con ilustraciones de material quirúrgico.

\section{Profesionalidad y Destreza}

Enlazado con el párrafo anterior, Abulcasis nos muestra a lo largo de toda la obra los valores médicos aprendidos de sus profesores y de otros sabios a los que leyó. Entre estos, destacan la conocida figura de Galeno, pero también la de Hipócrates. Hace mención al juramento Hipocrático hablando con el califa Abderrahmán III: "los médicos, señor, en el ejercicio de nuestra ciencia ni vemos, ni oímos, ni hablamos de lo visto $u$ oído: siguiendo a Hipócrates, nos lo veda nuestro juramento.»

Por otro lado, la profesión médica no requiere solo de amabilidad y compasión, "sin inmutarme - la frialdad es inherente y obligatoria en cirugía, 


\section{EL CIRUJANO DE AL-ÁNDALUS. APROXIMACIÓN A LA VIDA Y OBRA DE ABULCASIS DE LA MANO DE ANTONIO CAVANILLAS DE BLAS YAIZA FEI FERNÁNDEZ RAIGOSO}

tanto como la rapidez.» A veces se requiere un distanciamiento emocional para desempeñar un trabajo que presenta situaciones duras al estar en contacto directo con el sufrimiento y la muerte. Por ejemplo, reconoce Abulcasis cuando su padrastro enferma y dos médicos, profesores suyos de la aljama, van a visitarlo que "es curiosa la voz doctoral, la que empleamos los médicos al emitir diagnósticos o plantear hipótesis clínicas. La de ellos sonaba hueca y vanidosa, hecha de majestad.» La comunicación de malas noticias es una parte de la profesión que es importante aprender y, hoy en día, suele enseñarse en la universidad.

\section{Experiencia}

Abulcasis, siendo ya un médico consolidado, animado por su afán de conocimiento realiza un viaje encaminado a conocer qué y cómo se hacía en otros lugares, sobre todo, el tipo de cirugía que se hacía en Arabia, Constantinopla, Atenas, Roma o Napoles. Para ello, con la excusa de una visita a la Meca, realiza visitas a Toledo (en la época "Toledo y acero eran sinónimos»), donde hace acopio de material quirúrgico, visita un hospital de Creta, viaja a Jerusalén y llega a Bagdad, la ciudad más avanzada de la época, centro de saber y donde ejercen prestigiosos médicos de los que quiere aprender: "Cuando yo llegué funcionaban seis maristanes independientes y dos aljamas». Aunque también constata con pesar que «lo mismo que en Alejandría, la división religiosa y el fanatismo hicieron su aparición, y con ellos llegó la decadencia. Más o menos lo que está a punto de pasar en Córdoba». Cuando asiste a la descomposición del califato que ya llevaba previendo, considera que "lo mejor en épocas de penuria intelectual o cultural es concentrarse en el estudio, el trabajo y buscar acomodo entre gentes sencillas y apacibles, confiando en que una mala peste se lleve al tirano de turno».

Las charlas médicas con Realdo Conti, físico y cirujano que ejercía en Nápoles y con Avicena ya en su vejez pueden resumirse muy bien en una frase escrita en su encuentro con Joao Alves, cirujano lusitano: "Mi encuentro con Alves fue una experiencia inolvidable, que me confirmó en la idea de que no existe adelanto médico o quirúrgico que no sea avalado tras contrastarse por diferentes sabios».

Ya al final del libro, tras una vida dedicada a la medicina, Cavanillas nos cuenta de la mano del protagonista que «los médicos no nos jubilamos nunca por la edad, es la cabeza la que marca las pautas [...] Otra cosa son los cirujanos: aquí interviene el pulso».

Tabla 3. Relación de enfermedades y actos médicos aludidos en la obra El cirujano de Al Ándalus

\begin{tabular}{|c|c|}
\hline Enfermedad/ Acto médico & Breve extracto o resumen del procedimiento \\
\hline \multicolumn{2}{|r|}{ Enfermedades generales } \\
\hline $\begin{array}{l}\text { Anasarca como causa de la } \\
\text { Muerte de Hassan, padrastro } \\
\text { de Abulcasis }\end{array}$ & $\begin{array}{l}\text { Dicho de Al-Qurtubí: "La cavidad peritoneal se halla anegada por el líquido ascítico, los } \\
\text { riñones no drenan lo bastante y el edema se extiende como una pleamar viva, del final del } \\
\text { verano. De no evacuar el derrame enseguida la compresión que provoca lo asfixiará». (p. 143) }\end{array}$ \\
\hline $\begin{array}{l}\text { Absceso («flemón») en } \\
\text { la región anal del Califa } \\
\text { Abderramán }\end{array}$ & $\begin{array}{l}\text { "Contemplé su cráter verdoso del contenido purulento, las laderas levantadas, rojizas y la } \\
\text { base dura e inflamada». (p. 175) }\end{array}$ \\
\hline $\begin{array}{l}\text { Obesidad mórbida del rey } \\
\text { Sancho el Craso }\end{array}$ & $\begin{array}{l}\text { "[...] refería: ahogos, angustia matinal, micción difícil, mal de piedra, estreñimiento terco que } \\
\text { alternaba con diarreas incoercibles, palpitaciones desbocadas del corazón dentro del pecho, } \\
\text { podagra en ambos pies e impotencia general y coeundi». (p. 207). Mejoró con dieta }\end{array}$ \\
\hline $\begin{array}{l}\text { Corea o Baile de San vito en } \\
\text { una Niña de unos } 7 \text { años }\end{array}$ & $\begin{array}{l}\text { "Ardía en fiebre. Sus músculos contractos se estremecían en violentas sacudidas». [...] Estaba } \\
\text { obnubilada, era incapaz de responder a mis preguntas». (p. 227) }\end{array}$ \\
\hline
\end{tabular}




\section{EL CIRUJANO DE AL-ÁNDALUS. APROXIMACIÓN A LA VIDA Y OBRA DE ABULCASIS DE LA MANO DE ANTONIO CAVANILLAS DE BLAS YAIZA FEI FERNÁNDEZ RAIGOSO}

\begin{tabular}{|c|c|}
\hline Estruma o bocio de Galeno & $\begin{array}{l}\text { "Es mal que afecta al cuello a la altura de la nuez, se manifiesta en forma de tumor lobulado } \\
\text { o redondeado, blando y produce, además de las molestias propias de una masa en el pescuezo } \\
\text { que impide la deglución, síntomas somáticos». (p.228) }\end{array}$ \\
\hline $\begin{array}{l}\text { Neoplasma gástrico (Cáncer } \\
\text { de estómago) }\end{array}$ & $\begin{array}{l}\text { "[...] bajo la punta del esternón, se palpaba una masa dura, sensible, extensa, que ocupaba } \\
\text { también la parte izquierda». (p. 282) }\end{array}$ \\
\hline $\begin{array}{l}\text { Cáncer de estómago como } \\
\text { causa de su propia muerte } \\
\text { inminente }\end{array}$ & $\begin{array}{l}\text { "Es el neoplasma gástrico, un mal maligno e incurable que minará mis fuerzas y roerá mis } \\
\text { entrañas». ( } \mathrm{p} .400)\end{array}$ \\
\hline \multicolumn{2}{|r|}{ Enfermedades de transmisión sexual } \\
\hline Transmisión por miasmas & $\begin{array}{l}\text { "Sin duda existen mefíticas miasmas que medran en las zonas pudendas del hombre y la mujer } \\
\text { y que se transmiten en el acto de fornicación». (p. 316) }\end{array}$ \\
\hline $\begin{array}{l}\text { Peste blanca (Sífilis). } \\
\text { (Muerte de Al-Mansur) }\end{array}$ & $\begin{array}{l}\text { Su agonía fue espantosa: dolores terroríficos lo hacían blasfemar de Alá y de su profeta, me } \\
\text { Ilamaba a gritos para que lo calmase». (p.364) }\end{array}$ \\
\hline \multicolumn{2}{|r|}{ Epidemias } \\
\hline Brote de peste en el barco & $\begin{array}{l}\text { "Alli, chapoteando entre el agua de mar que trasudaban las cuadernas, deyecciones humanas } \\
\text { y ratas hambrientas, vio a un hombre agonizante y varios emaciados o famélicos» } \\
\text { "Ante la peste negra nos hayamos inermes» (p.195) }\end{array}$ \\
\hline Peste & $\begin{array}{l}\text { "Raro era el siglo en el que, desde la más remota antigüedad, no ocurrían dos o tres epidemias } \\
\text { del terrible mal». } \\
\text { "Cuando el hombre inculto ignora el origen de un mal tiende a buscar culpables entre aquellos } \\
\text { que se odian o detestan. Si se concentran miles de incultos, se actúa contra tarados o minorías } \\
\text { étnicas». (p.366) }\end{array}$ \\
\hline \multicolumn{2}{|r|}{ Traumatismos* } \\
\hline Suturas & $\begin{array}{l}\text { "No hace mucho traté a su marido de un descalabro- se cayó de la mula cuando regresaba del } \\
\text { huerto familiar-y hube de suturar su cuello cabelludo.» (p.16) }\end{array}$ \\
\hline Fractura de muñeca & $\begin{array}{l}\text { "Bajo la ayuda del narcótico, enderecé los huesos desplazados con una férula de madera } \\
\text { dorsal y otra ventral. Aseguré todo con vendas y, tras comprobar por su color que la sangre } \\
\text { llegaba bien a los dedos, despedí al paciente sin cobrarle». (p.165) }\end{array}$ \\
\hline $\begin{array}{l}\text { Extirpación de flecha a Al- } \\
\text { Hakán }\end{array}$ & $\begin{array}{l}\text { "Al retirar la sonda salió un chorretón de pus amarillo verdoso, denso, de olor fétido. Era } \\
\text { evidente que la supuración no drenaba de manera adecuada por el estrecho orificio». (p.300) }\end{array}$ \\
\hline
\end{tabular}

\section{Enfermedades y procedimientos}

"Cuando el hombre inculto ignora el origen de un mal tiende a buscar culpables entre aquellos que se odian o detestan.

Si se concentran miles de incultos, se actúa contra tarados o minorías étnicas»

La obra es abundante en descripción de enfermedades (Tabla 3) y actos médicos (Tabla 4). Entre los primeros, aparecen recogidos entidades nosológicas como anasarca, absceso, obesidad, «baile de San Vito», el bocio, neoplasias, la peste blanca (sífilis), la peste, y algunos traumatismos. Entre los procedimientos descritos en la tabla 4 destacan una traqueotomía, una operación de catarata, probablemente de las primeras llevadas a cabo con éxito en nuestro país, bajo los efectos de la "esponja soporífera» cuyo uso aprendió en su viaje a Bagdad. También se citan trepanaciones, paracentesis, trombectomía, apendicectomía y extracción de veneno de víbora. 


\section{EL CIRUJANO DE AL-ÁNDALUS. APROXIMACIÓN A LA VIDA Y OBRA DE ABULCASIS DE LA MANO DE ANTONIO CAVANILLAS DE BLAS YAIZA FEI FERNÁNDEZ RAIGOSO}

Tabla 4. Procedimientos médicos y quirúrgicos contenidos en la obra El cirujano de Al Ándalus

\begin{tabular}{|c|c|}
\hline Procedimiento & Breve extracto o resumen del procedimiento \\
\hline \multicolumn{2}{|r|}{ Cabeza y cuello } \\
\hline $\begin{array}{l}\text { Traqueotomía en niña } \\
\text { atragantada por una semilla } \\
\text { de melocotón. }\end{array}$ & $\begin{array}{l}\text { "Sin dudar, centré la barbilla de manera que enfrentara el yúgulo esternal, extendí } \\
\text { fuertemente el cuello y hundí el escalpelo en su piel por debajo de la nuez, profundizando } \\
\text { hasta la tráquea.» (p.19) }\end{array}$ \\
\hline $\begin{array}{l}\text { Operación de catarata de la } \\
\text { mano de Ibn Safi en su viaje } \\
\text { a Fez }\end{array}$ & $\begin{array}{l}\text { «Entonces, sin dudar, con rara maestría, incidió en la línea que separa el cristalino de la túnica } \\
\text { alba, de manera sutil, extraordinariamente delicada...» (p.116) }\end{array}$ \\
\hline $\begin{array}{l}\text { Extracción dental por un } \\
\text { absceso a la madre de un } \\
\text { muladí empleado del zoco } \\
\text { del pescado }\end{array}$ & $\begin{array}{l}\text { "Enseguida abrí su boca, identifiqué la muela cariada y putrefacta y la extirpé con gran } \\
\text { facilidad con la tenaza, pues estaba medio suelta». (p. 160) }\end{array}$ \\
\hline Estrumectomía & $\begin{array}{l}\text { "Pasé cuatro ligaduras de seda, que amarré con fuerza, seccioné los vasos y extraje con la } \\
\text { mayor facilidad el tumor». (p.228) }\end{array}$ \\
\hline Trepan & $\begin{array}{l}\text { "En medio de grandes convulsiones, el accidentado se me fue de las manos por no disponer de } \\
\text { un trépano adecuado con que evacuar el derrame interior que sin duda tenía y que presionaba } \\
\text { el cerebro comprometiéndolo hasta causar su muerte». (p.252) } \\
\text { «Busqué el parietal derecho al ser el lado derecho el que padecía fuertes convulsiones, pero en } \\
\text { el organismo las cosas no son como parecen». (p.260) }\end{array}$ \\
\hline \multicolumn{2}{|r|}{ Abdomen e ingle } \\
\hline $\begin{array}{l}\text { Paracentesis ( Muerte } \\
\text { de Hassan, padrastro de } \\
\text { Abulcasis) }\end{array}$ & $\begin{array}{l}\text { "Con maestría, Al-Qurtubí sacó el punzón y en su lugar dejó un junco grueso y hueco. Por } \\
\text { el caño surgió un chorro de líquido ambarino, denso y caliente, que enseguida llenó una } \\
\text { palangana». (143) }\end{array}$ \\
\hline $\begin{array}{l}\text { Trombectomía hemorroidal } \\
\text { en un hombre viejo, jefe de } \\
\text { una tribu sahariana }\end{array}$ & $\begin{array}{l}\text { "La intervención, con la ayuda de la esponja soporífera, fue simple [...], ausencia de dolor } \\
\text { cuando practiqué la generosa incisión sobre la adelgazada mucosa hemorroidal que envolvía } \\
\text { el trombo». (p. 162) }\end{array}$ \\
\hline $\begin{array}{l}\text { Apendicectomía (Cólico } \\
\text { miserere o Apendicitis) }\end{array}$ & $\begin{array}{l}\text { "Fue entonces cuando palpé una masa dura, una especie de aglomerado purulento que surgía } \\
\text { del intestino ciego. Pasé una ligadura de len grueso sobre su base y lo extirpé». (p.352) }\end{array}$ \\
\hline \multicolumn{2}{|r|}{ Extremidades } \\
\hline $\begin{array}{l}\text { Trombectomía por el } \\
\text { cirujano lusitano Joao Alves. }\end{array}$ & $\begin{array}{l}\text { "Tras extirparlo del conducto ocluido, ligó con seda doble y resecó lo dañado del vaso, pues } \\
\text { afirmaba que, de no hacerlo, se reproducía el mal». (p. 320) }\end{array}$ \\
\hline $\begin{array}{l}\text { Extracción de veneno de } \\
\text { víbora a un camellero }\end{array}$ & $\begin{array}{l}\text { "coloqué un torniquete en la raíz del muslo usando una sábana, le cogí el miembro herido } \\
\text { aplicando la boca, succioné con fuerza en los orificios tratando de aspirar todo el veneno } \\
\text { posible». (p. 413) }\end{array}$ \\
\hline
\end{tabular}

\section{Conflicto ciencia y religión}

"iSólo hay un dios, Alá, y Mahoma es su profeta!»

No se puede entender completamente la historia sin entender la religión que tanto influye en la historia y su transcurso. Desde joven, Abulcasis siente los antagonismos entre ciencia y religión que nos han llegado hasta hoy con grandes dificultades de armonización: "Mala cosa, pensé, mezclar ciencia y religión». Dicho esto, a nivel personal, valora mucho más su profesión y su deber médico que su religión y, al mismo tiempo, no ve por qué tienen que ser antagónicos, «mi religión son las mujeres y hombres que padecen. Soy islamita, pero no tengo otra fe que la que dicta el sentido común, la ciencia y el amor a los que lo merezcan.»

El eje principal al inicio del estudio de medicina hoy en día no es sino la anatomía del cuerpo humano, seguida de la fisiología, la fisiopatología, la terapéutica y la prevención. Un tema muy tratado de este aspecto es el de las disecciones. 


\section{EL CIRUJANO DE AL-ÁNDALUS. APROXIMACIÓN A LA VIDA Y OBRA DE ABULCASIS DE LA MANO DE ANTONIO CAVANILLAS DE BLAS YAIZA FEI FERNÁNDEZ RAIGOSO}

El protagonista muestra interés en descubrir el interior del cuerpo humano y estudiar su anatomía, "¿Quién pudiera disponer de un cadáver?». Sin embargo, se ve muy limitado ya que la religión está en contra de las disecciones, y solo encuentra un resquicio de conocimiento de la mano de un taxonomista que le permite observar el interior de distintos animales. Este conflicto se observa a lo largo de la novela. En una conversación con su amigo napolitanto Realdo Conti comenta como en los reinos cristianos se avanza a pasos agigantados en el campo anatómico precisamente porque su religión permite las disecciones y le afirma que "daría cualquier cosa por tener su suerte».

Por otro lado, contrario a la imagen negativa que hoy en día se asocia con el Islam debido en su mayoría a radicales y extremistas, en este libro se nos da una valiosa lección: somos las personas las que hacemos el mal si queremos, el Islam puede ser muy tolerante y abierto y en verdad lo fue. En particular en la Córdoba de Abulcasis donde convivían musulmanes, cristianos y judíos, "afortunadamente vivimos en Al-Ándalus, una tierra donde hay más permisividad que en cualquier otra parte del Islam.» Si bien es cierto que él mismo también teme algunas posturas extremistas en algunas regiones y sectores de la sociedad: «nuestra religión es joven, está oscurecida por ciertos fanatismos, un sarpullido que confío desaparezca poco a poco, igual que un tabardillo.»

Finalmente, otro tema controvertido y tratado desde una manera novedosa es el de la poligamia. La poligamia es un tema ampliamente criticado en la cultura occidental, principalmente debido a que sigue imperando la perspectiva de los valores cristianos. Independientemente de la opinión respecto a esto, Abulcasis razona con el padre de su tercera esposa, de familia cristiana, de la siguiente manera: «Mis dos esposas son más libres que la tuya y que la amante que sustentas." Además el mismo reconoce que "no es nada fácil poseer cuatro esposas y cinco concubinas. Ello requiere desde luego riqueza, pero sobre todo nobleza" y dice saber "que el Alcorán habla de sometimientos e incluso castigos a la mujer díscola o revoltosa, pero yo no comulgo con ello. Poner la mano sobre la mujer, si no es para acariciarla, es de villanos». En relación a sus esposas, vemos también la tolerancia religiosa: su primera mujer es judía, su tercera cristiana y la segunda y la cuarta musulmanas; "jamás hubo discusiones o malos gestos entre ellas a la hora del amor».

En cuanto al velo (traducción que se hace del hijab) se nos menciona de pasada. Como una parte más de la vestimenta pero sin ser crucial. La madre de Abulcasis, Zulema, no suele llevar el pelo cubierto, sin embargo, durante un viaje por tierras cristianas, se vio tan observada: «la devoraban con la vista el mocetón, el militar, el sacerdote y hasta el hombre casado" que "se vio obligada a cubrirse con el hijab, algo que ni siquiera hace en el arrabal». Por otra parte, ya hemos dicho que Córdoba era mucho más tolerante y por el oriente empezaban a surgir extremismos, en este sentido en su viaje a conocer a Avicena al final de su vida, de la estancia en Alejandría dice: «afortunadamente no hizo calor, pues el cumplimiento de las leyes coránicas, aplicadas allí con rigor, obligaba a las mujeres a ir cubiertas hasta las cejas».

Como curiosidad y para finalizar este apartado, el islam y la salud son dos conceptos que están intrínsecamente relacionados: de hecho de la raíz árabe s-I-m (سلم) derivan términos como salam («paz»), salamh (salud), salim (sano), islam (sometimiento) o muslim (musulman) ${ }^{8}$.

\section{Discusión}

Hay que ser sinceros siempre que se pueda: el libro comienza a ritmo lento, pausado, relajado. Para algunos, esto no supondrá un problema, ya que disfrutarán con la cuidada descripción de los paisajes y los recuerdos infantiles de un Abulcasis (más bien Abul Qasim) ya viejo, narrador y escritor de su autobiografía. Sin embargo, para los impacientes que quieren ir directos a la historia, la prueba de que esta novela no se hará pesada 


\section{EL CIRUJANO DE AL-ÁNDALUS. APROXIMACIÓN A LA VIDA Y OBRA DE ABULCASIS DE LA MANO DE ANTONIO CAVANILLAS DE BLAS YAIZA FEI FERNÁNDEZ RAIGOSO}

tampoco se hace esperar mucho. De repente, asistimos a una traqueotomía en una niña atragantada. Y, así de simple como nos hace parecer Abulcasis su trabajo, nos cuenta la historia de toda una vida dedicada a la medicina.

La medicina, tan protagonista o más que el mismo Abulcasis, se nos presenta como observación y trabajo constante, práctica y experiencia. Un concepto que no ha cambiado mucho en diez siglos. Y teniendo en cuenta la época, los viajes narrados resultan impresionantes, son travesías largas a paisajes magníficos y bastante lejanos que aún hoy en día no muchos pueden realizar.

Entre el argumento principal que podemos indicar como la vida del gran médico, se intercalan escenas de la situación política del reino. Al igual que se deja entrever el comienzo del extremismo en algunas posiciones que profesan el Islam. Sin embargo, la visión que el narrador nos ofrece del Islam es muy diferente y refrescante, nos abre la mente cegada por los atentados terroristas y el extremismo islámico del que tanto se habla hoy en día. Es casi increíble como hasta la poligamia se ve con otros ojos, pasa de ser cosa de bárbaros a un razonamiento lógico y práctico.

El libro alcanza brillantez narrativa en las páginas referentes a una plaga que asoló Córdoba. Una situación que, cuando la leí, sentí cercana hasta donde el escritor es capaz de transmitir. Ahora, en pleno confinamiento por la COVID-19, es mucho más fácil de imaginársela, solo hace falta vivir y poder mirar por una ventana. Mientras miras la calle vacía, imaginar la calle llena de gente, conscientes todos de que cualquiera de esas personas puede tener la enfermedad y transmitirla. Sentir preocupación, incluso miedo, de estar contagiado, de poder contagiar a alguien, del futuro incierto. Si todavía cuesta con eso, siempre puede recurrirse a internet y buscar noticias de Madrid, Estados Unidos o el mundo a principios de 2020.

Me pregunto o, en verdad, creo estar segura de que, como en la novela, la situación, aunque muy dramática, es pasajera. Un capítulo más en el libro y en su vida. Es más, para cuando alguien más lea esto, probablemente tenga que hacer un poco de memoria para saber cuál es su significado.

Abulcasis es sensible a los efectos del tiempo pues, aunque insiste en que "los médicos no nos jubilamos nunca por la edad, es la cabeza la que marca las pautas», se da cuenta de que la vida ha ido pasando y sus capacidades se han ido perdiendo, por ejemplo, en la visita a un amigo años después, "uno no se da cuenta de que envejece pues, viéndose en el espejo a diario, se hace al propio rostro y a sus lentas arrugas. Por ello, supone una severa conmoción ver a un amigo treinta y un años después."

Nosotros, junto con el protagonista y quizá también el escritor, somos conscientes del paso de su vida, desde sus primeros recuerdos hasta la certeza de su muerte inminente. Los primeros atisbos se entrevén a los cincuenta y un años, «quizá conozcáis la sensación si tenéis esa edad o pasasteis por ella. De repente os parece que lo habéis hecho todo y no lograsteis nada, que todos vuestros actos son mecánicos, que ya no sois capaces de crear ilusión, que vuestras fibras se endurecen y nunca más volveréis a gozar de carne tierna». Y, «después de cincuenta y cinco años de ejercer la más noble de las profesiones, conozco la enfermedad que sufro", neoplasma gástrico, mejor conocido como cáncer de estómago. Y, como él, vamos pasando las páginas y, casi sin darnos cuenta, llegamos al final, «mi tiempo se termina y me parece justo, pero mentiría si dijese que lo acepto de buen grado».

\section{Agradecimientos}

La autora manifiesta su agradecimiento al Prof. Agustín Hidalgo por las orientaciones para la elaboración del artículo.

\section{Conflictos de intereses}

La autora declara que no tiene conflictos de interés.

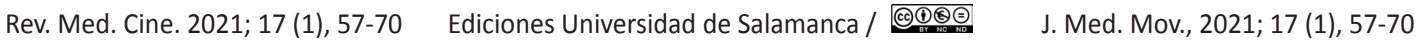




\section{EL CIRUJANO DE AL-ÁNDALUS. APROXIMACIÓN A LA VIDA Y OBRA DE ABULCASIS DE LA MANO DE ANTONIO CAVANILLAS DE BLAS YAIZA FEI FERNÁNDEZ RAIGOSO}

\section{Referencias}

1. Antonio Cavanillas de Blas - Editorial Verbum [Internet]. Editorial Verbum. 2020 [citado 30 septiembre 2020].

2. Vernet Ginés J. Historia de la ciencia española. Edición Facsimil. Barcelona: ALTA FULLA; 1998

3. Cavanillas de Blas A. El cirujano de Al-Ándalus. Madrid: La Esfera de los libros; 2009.

4. Rodríguez-Sendín JJ. Definición de «profesión médica», "profesional médico/a» y "profesionalismo médico». Educ Med 2010; 13 (2): 63-6.

5. Gargantilla P. Breve Historia de la Medicina. Del Chamán a la Gripe A. Madrid: Nowtilus; 2011.

6. Abulcasis. Real Academia de la Historia. [Internet]. Dbe.rah.es. 2020 [citado 2 octubre 2020].
7. Hidalgo A. Algunas características generales de los textos literarios relacionados con la enfermedad. Rev Med Cine [Internet] 2016; 12(2):78-81.

8. Literatura Médica Islámica en al-Andalus. Balansiya [Internet]. 2014 [citado 2 octubre 2020].

9. López Piñero JM. Breve Historia de la medicina. Madrid: Alianza Editorial; 2000.

10. Riera J. Historia, Medicina y Sociedad. Madrid: Pirámide; 1985.

11. Avicena. Poema de la Medicina. Salamanca: Junta de Castilla y León / Europa Artes Gráficas; 1999.

12. TRAUMATISMO, radicación. Etimologías de Chile - Diccionario que explica el origen de las palabras [Internet] 2020 [citado 2 octubre 2020].

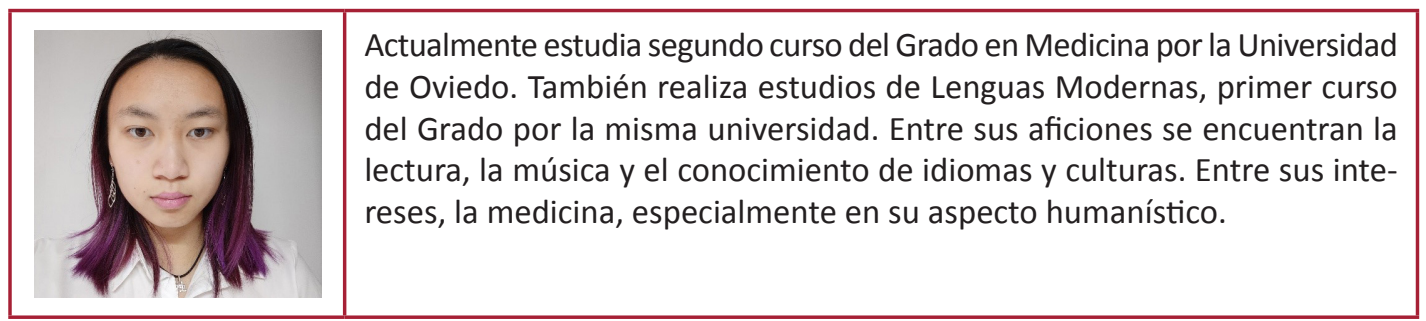

